\title{
Hybrid approach to ventral wall hernia repair: a single- institution cohort study
}

\author{
Sara Jamel (D) - Sherif Mohamad Hakky · Karina Tukanova · Sarah Huf · Sheraz Markar · Sanjay Purkayastha
}

Received: 30 October 2019 / Accepted: 8 September 2020 / Published online: 16 October 2020

(C) The Author(s) 2020

\begin{abstract}
Summary
Background Ventral hernias pose a substantial challenge for surgeons. Even though minimally invasive surgery and hernia repair have evolved rapidly, there is no standardised method that has been widely accepted as standard of practice. Hybrid ventral hernia repair (HVR) is an alternative surgical approach, which has not been adopted widely to date. It combines laparoscopic mesh insertion with closure of the hernia defect. The aim of this retrospective cohort study is to evaluate short- and long-term outcomes in patients undergoing HVR.
\end{abstract}

Methods Between October 2012 and June 2016, 56 HVRs were performed at St Mary's Hospital, Imperial College London. The medical records of these patients were reviewed retrospectively for demographics, comorbidities, previous surgeries, operative technique, complications and recurrences over a 3year follow-up.

Results HVRs were performed by four surgeons. Mean age was 48 years with a mean body mass index (BMI) of $32.8 \mathrm{~kg} / \mathrm{m}^{2} .71 .4 \%$ had incisional hernias and $28.6 \%$

Video online The online version of this article contains a video. The article and the video are online available (https://doi.org/10.1007/s10353-020-00671-y). The video can be found in the article back matter as "Electronic Supplementary Material".

S. Jamel, MRCS, BSc $(\bowtie) \cdot \mathrm{K}$. Tukanova, MBBS ·

S. Huf, MRCS, PhD · S. Markar, MRCS, PhD, PhD, MA, MSc .

S. Purkayastha, FRCS, MD

Division of Surgery, Department of Surgery and Cancer, Imperial College London, 10th Floor QEQM Building, St Mary's Hospital, South Wharf Road, London, W2 1NY, UK s.jamel@imperial.ac.uk

\section{S. M. Hakky, MSC, MD, FRCS}

Department of Bariatric Surgery, Imperial College Healthcare NHS Trust, St Mary's Hospital, South Wharf Road, London, W2 1NY, UK had primary hernias. The number of hernia defects ranged from 1 to 4 , with average defect size $42.9 \mathrm{~cm}^{2}$ (range $8-200 \mathrm{~cm}^{2}$ ). Adhesiolysis was performed in $66.1 \%$ of patients. Recurrence occurred in 2 patients (3.6\%), $16.1 \%$ of patients developed postoperative seroma, $0.3 \%$ had respiratory complications, $0.3 \%$ had paralytic ileus and $0.2 \%$ had urinary retention. Only 2 patients required epidural postoperatively, both had a defect size of $150.0 \mathrm{~cm}^{2}$. There were no reoperations within 90 days. Mean length of hospital stay was 2 days (1-10 days). Over the follow-up period, 2 patients $(3.6 \%)$ developed chronic pain.

Conclusion The hybrid technique is safe and feasible, and has important benefits including low rates of seroma formation, chronic pain and hernia recurrence. Future investigations may include randomised controlled trials to evaluate the benefits of VHR, with careful assessment of patient-reported outcome measures including quality of life and postoperative pain.

Keywords Hybrid · Ventral hernia - Laparoscopy • Incisional · Primary $\cdot$ Pain $\cdot$ Recurrence

\section{Introduction}

Ventral hernias, whether primary or incisional or recurrent, are common, and often require surgical repair. Incisional hernias occur in approximately $2-20 \%$ of abdominal incisions, with postoperative wound infection being a significant risk factor [1]. Approximately 20 million hernias are repaired every year around the world and over 100,000 in the UK, which carries a significant financial burden and morbidity cost [2-4].

The traditional approach to repair of abdominal wall hernias has been open, with laparoscopic repair first introduced by LeBlanc in 1993 [5]. However, there is an on-going debate regarding the optimal manage- 
ment of ventral hernias, whether primary or recurrent. Currently, the surgical techniques employed for repair of primary and recurrent hernia are similar. Gold standard repair aims at reinforcing the hernial defect, with mesh placement posterior to the fascia. Application of the principles of Pascal's law is crucial to the biomechanics of mesh placement and hernia repair. Anatomical closure will cause the intra-abdominal pressure to be transmitted equally in all directions, which focuses the pressure on hernia edges. In the case of onlay mesh repair, the intra-abdominal pressure forces will act to push the mesh outwards. On the other hand, with intraperitoneal mesh the intraabdominal pressure forces compress the mesh against the anterior abdominal wall, thus acting in favour of the repair [6].

Most laparoscopic ventral hernia repairs use the technique of placing an intraperitoneal onlay mesh. This leads to bridging of the hernia defect following reduction of the hernia contents, but leaves the hernia sac in situ. Laparoscopic repair is thought to have the benefit of reducing postoperative pain and wound infection, and to be associated with shorter hospital stay in comparison to open hernia repair. However, this is not supported by the RCT by Eker et al. [7] showing no significant difference in recurrence rate or postoperative pain and a higher complication rate for the laparoscopic technique. Similarly, Liang et al. [8] showed that although the laparoscopic technique reduced the risk of wound complications, there was no significant effect on seroma and recurrence.

Bridging of the hernial defect commonly leaves an unsightly swelling at the hernia site, referred to as tissue eventration, which is retained preperitoneal fat or hernia sac that extends beyond the boundaries of the anterior abdominal wall fascia. By re-approximating the fascia, the dead space that contained the hernia sac is reduced. Minimising dead space potentially decreases the likelihood of seroma formation. With the fascial gap closed, there is minimal space for mesh or tissue to protrude beyond the anterior fascial plane, which decreases the likelihood of eventration. Eventration can be associated with decreased patient satisfaction following hernia repair, as it can lead to pain and perceived recurrence by patient $[9,10]$.

At our institution, surgeons have been preforming a hybrid repair combining both an open and a laparoscopic approach. This allows i) exposure of the hernia defect and complete reduction, ii) excision of the sac and iii) closure of the abdominal wall and intraperitoneal mesh reinforcement. We hypothesize that we can achieve the benefits of defect closure with large intraperitoneal mesh while decreasing seroma formation and maintaining low rates of recurrence and postoperative pain.

\section{Methods}

This study was a retrospective cohort study of patients who underwent HVR at a single institution between October 2012 and June 2016. IRB approval and written consent were not required as all data are fully anonymised.

Information was collected on baseline characteristics such as age, gender, body mass index, American Society of Anaesthesiologists classification, and the number and size of hernia defects. The operative details included were operative technique, operative time, extent of adhesions, and perioperative complications and their management. Data on the length of in-hospital stay as well as 30-day morbidity and mortality were collected retrospectively.

Only elective operations were included in the study. Primary outcome parameters were recurrence after a median follow-up of 4 years. Secondary outcomes were chronic pain requiring treatment, intraoperative visceral injury, seroma/haematoma formation, reoperation, readmission, infection, prolonged wound healing and general complications.

All patients underwent a clinical follow-up at 3-6 months to assess for recurrence and long-term complications.

\section{Surgical technique}

The surgical approach was standardised for all included patients. All patients were operated on in the supine position under general endotracheal anaesthesia and received preoperative antibiotics 30 minutes prior to incision. The abdominal cavity was entered laparoscopically using an optical entry technique 12$\mathrm{mm}$ port, which was inserted in the left upper quadrant at Palmer's point. Two further laparoscopic ports were inserted under vision (5-mm ports); the position of these two ports depended on the location of the hernia (Fig. 1).

First, all hernia defects were identified laparoscopically, with adhesiolysis carried out in some cases. Thereafter, the hernia sac content was reduced into the abdominal cavity and the sac content was freed of adhesions. Upon reduction of all hernial contents into the abdominal cavity, pneumoperitoneum was reduced to $4 \mathrm{mmHg}$ to allow careful and accurate measurement of defect size.

Subsequently, the open approach whereby an incision is made over the hernia defect, utilising the previous scar. The incision made is large enough to allow adequate dissection of the hernia sac and exposure of the fascial borders. The sac is then excised and hernia edges are cleared. Extracorporeal transfacial closure of the hernia defect was performed using either loop PDS or interrupted Ethibond (Fig. 1).

This was then followed by a return to laparoscopy, where the closure was re-assessed. At that time, the mesh was appropriately sized and prepared for inser- 
Fig. 1 a Red Trocar is placed at Palmar's point (optical entry site to abdominal cavity). Commonest working laparoscopic trocar positions, blue. Variation of this is indicated in green. Red Trocar is at Palmar's point (optical entry to abdominal cavity). Trocars placed laterally, away from the hernia defect. b Laparoscopic adhesionolysis and defect identification with an open component of sac excision and closure
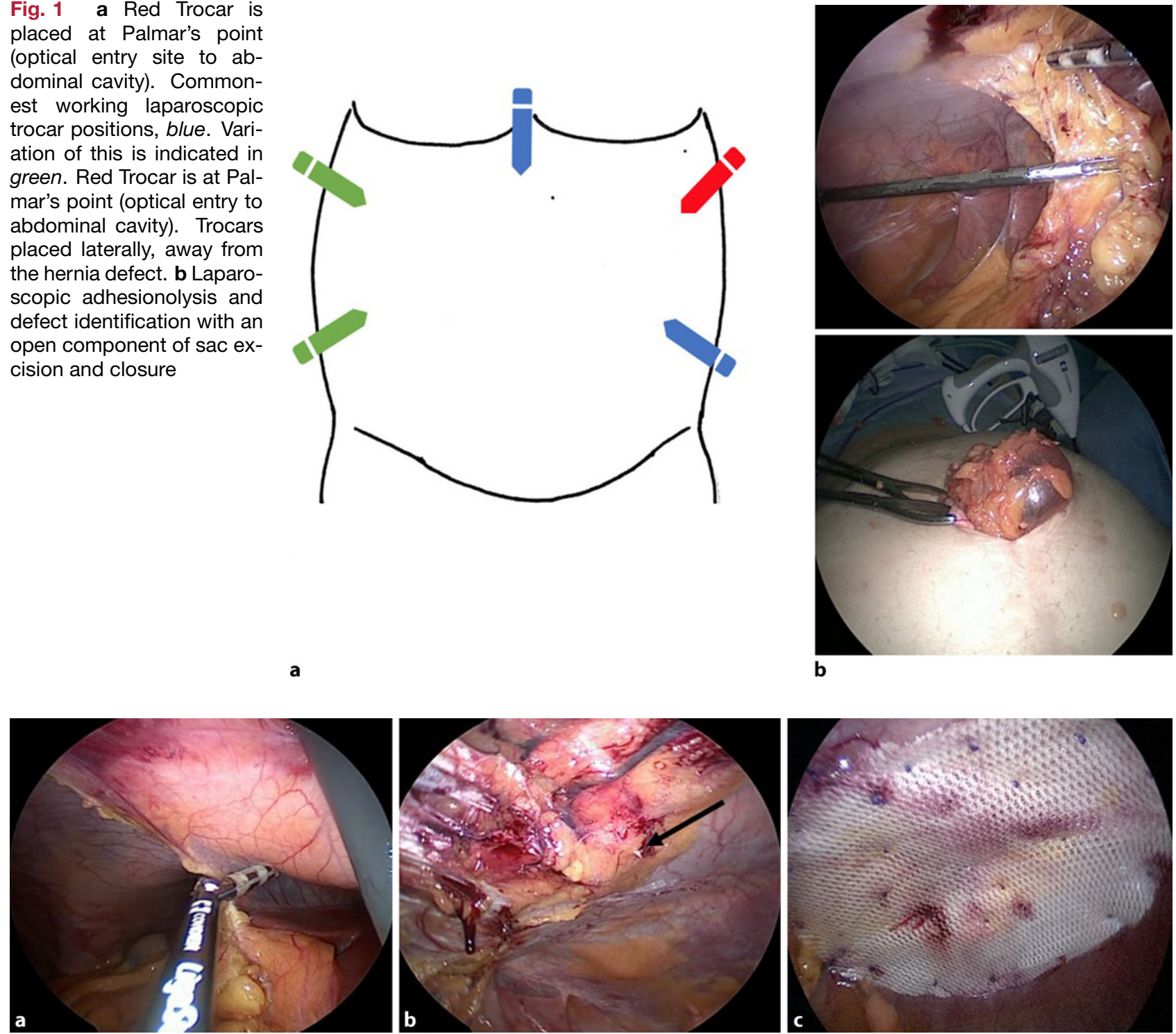

Fig. 2 Clearing the abdominal wall for mesh placement. a Taking down the falciform ligament, $\mathbf{b}$ defect sizing (needle indicated with arrow), $\mathbf{c}$ mesh placed with crowing configuration tacks

tion with 2/0 Prolene to allow the mesh to be lifted up with a parachute technique to ensure that the collagen side is against the abdominal cavity.

The mesh was handled minimally extracorporeally to reduce the risk of mesh infection. The mesh was secured on the anterior abdominal wall using a doublecrown configuration technique with multiple 5-mm titanium spiral tacks (Protack; Covidien, MA) or SecureStrap (Ethicon Securestrap ${ }^{\mathrm{TM}}$ ) placement along it borders every 2 to $3 \mathrm{~cm}$. Abdominal insufflation pressure was reduced prior to mesh securing to abdominal wall. At the end of the operation, trocars were withdrawn under vision and pneumoperitoneum was abolished (Fig. 2).

A video showing surgical technique steps is provided in the electronic supplementary material.

\section{Results}

Fifty-six patients underwent HVR with surgery performed by four surgeons. The mean age was 48 years with a mean BMI of $32.8 \mathrm{~kg} / \mathrm{m}^{2} .71 .4 \%$ had incisional hernias and $28.6 \%$ had primary hernias. The number of hernia defects ranged from 1 to 4 , with an average defect size of $42.9 \mathrm{~cm}^{2}$. Adhesiolysis was performed in $66.1 \%$ of patients. A serosal tear occurred in one case which required intraoperative laparoscopic suturing with no further complication (Table 1).

Two patients $(3.6 \%)$ developed chronic pain postoperatively and 2 patients developed recurrence over a median 4-year follow-up period. Both recurrences occurred in patients who had had Physiomeshes inserted (Table 2).

Postoperative complications: Clavien-Dindo grades 1: $19.7 \%$, grade 2: $5.4 \%$, grades 3,4 and 5: none. $16.1 \%$ 
Table 1 Characteristics of patients undergoing repair of ventral hybrid hernia

\begin{tabular}{|c|c|}
\hline $\begin{array}{l}\text { Total patient number } \\
\text { Characteristic }\end{array}$ & $56, n(\%)$ \\
\hline Age, years & 50.8 (range $34-75$ years) \\
\hline$B M I, k g / m^{2}$ & 32.8 (range $\left.21.2-49 \mathrm{~kg} / \mathrm{m}^{2}\right)$ \\
\hline Hernia size, $\mathrm{cm}^{2}$ & 44.7 (range $8-200 \mathrm{~cm}^{2}$ ) \\
\hline \multirow{4}{*}{$\begin{array}{l}\text { ASA, (American Society of } \\
\text { Anesthesiologists physical } \\
\text { status) }\end{array}$} & ASA $112(21.5 \%)$ \\
\hline & ASA 237 (66.1) \\
\hline & ASA 37 (12.5\%) \\
\hline & ASA 4 - \\
\hline \multirow[t]{4}{*}{ Hernia type } & Primary hernia $16(28.6 \%)$ \\
\hline & Incisional hernia 40 (71.4\%) \\
\hline & Recurrent hernia 7 (12.5\%) \\
\hline & Re-recurrences $5(8.9 \%)$ \\
\hline \multirow{5}{*}{$\begin{array}{l}\text { European Classification of } \\
\text { Incisional Hernias (M1 } \\
\text { Subxyphoidal, M2 Epigastric, } \\
\text { M3 Umbilical, M4 } \\
\text { Infraumbilical, M5 Suprapubic) }\end{array}$} & M1 0 \\
\hline & M2 11 (27.5\%) \\
\hline & M3 12 (30.0\%) \\
\hline & M4 $12(30.0 \%)$ \\
\hline & M5 15 (37.5\%) \\
\hline \multirow[t]{4}{*}{ Mesh type } & Physiomesh (Ethicon, UK) 24 (42.8\%) \\
\hline & $\begin{array}{l}\text { Parietex }{ }^{\mathrm{TM}} \text { Composite (Medtronics, UK) } \\
5(8.9 \%)\end{array}$ \\
\hline & Ultrapore (Medtonic, UK) 1 (1.8\%) \\
\hline & Symbotex $^{\mathrm{TM}}$ (Medtronic, UK) 12 (21.4\%) \\
\hline \multirow[t]{3}{*}{ Adhesiolysis } & None $33(59.0 \%)$ \\
\hline & Simple $15(26.7 \%)$ \\
\hline & Complex 8 (14.2\%) \\
\hline Serosal tear & $1(1.8 \%)$ \\
\hline
\end{tabular}

Table 2 Table highlighting the primary outcome of recurrence and demographics of the cases with recurrence

\begin{tabular}{l|l|l|l|l}
\multicolumn{2}{l}{$\begin{array}{l}\text { Primary outcome } \\
\text { Recurrence }\end{array}$} & No. of patients (\%) \\
Recurrence case description & $2(3.5 \%)$ \\
\hline BMI & Patient 1 & Patient 2 \\
\hline Defect size & 22.4 & 36.5 \\
\hline Mesh used & 165 & 200 \\
\hline $\begin{array}{l}\text { Previous } \\
\text { surgery }\end{array}$ & $\begin{array}{l}\text { Physio } \\
\text { Open paraumbilical hernia }\end{array}$ & $\begin{array}{l}\text { Physio } \\
\text { recurrence }\end{array}$ \\
\hline
\end{tabular}

Table 3 Distribution of postoperative outcomes in patients undergoing repair of ventral hybrid hernia

\begin{tabular}{|l|l|}
\hline $\begin{array}{l}\text { Clavien-Dindo grading } \\
\text { Grade I }\end{array}$ & No. of patients (\%) \\
\hline $\begin{array}{l}\text { Wound seroma } \\
\text { Surgical site infection }\end{array}$ & $9(16.1 \%)$ \\
\hline Grade II & $2(3.6 \%)$ \\
\hline Ileus & $1(1.8 \%)$ \\
\hline Respiratory complications & $2(3.6 \%)$ \\
\hline Grade III-V & 0 \\
\hline Re-admission & $1(1.8 \%)$ \\
\hline Mean length of hospital stay, days & 2 (range 1-10 days) \\
\hline
\end{tabular}

Table 4 Table highlighting the postoperative analgesia used after hybrid repair

\begin{tabular}{ll}
\hline Postoperative pain management & No. of patients (\%) \\
\hline Epidural & $3(5.4)$ \\
\hline Patient controlled Analgesia CA & $10(17.8)$ \\
\hline Intravenous analgesia & $3(5.3)$ \\
\hline Oral analgesia & $41(73.2)$
\end{tabular}

patients developed postoperative seroma, $0.3 \%$ had respiratory complications, $0.3 \%$ had paralytic ileus and $0.2 \%$ had urinary retention. The readmission rate was $1.8 \%$ and this was due to postoperative haematoma at day 10 . This was managed conservatively and the patient discharged within 1 day. The two cases of chronic pain had Protack used and one had combination of Protack and secure strap (Table 3). These patients did not demonstrate postoperative complications and re-admission; however, both required postoperative intravenous patient-controlled analgesia.

The mean length of hospital stay was 2 days (1-10 days), with $51.7 \%$ of patients having a length of stay of 1 day only. The patient who stayed for 10 days had a defect size of $\geq 150 \mathrm{~cm}^{2}$ and developed postoperative type II respiratory failure (Table 3). $94 \%$ of patients were followed up by clinical assessment.

There was no mortality in our cohort. Table 4 highlights the postoperative analgesia used, showing that the majority of patients were manged with oral analgesia, facilitating early discharge. All patients had lowdose spinal analgesia with diamorphine as standard of care during surgery. Only 2 patients required epidural postoperatively; these patients had larger defects size of 165 and $150 \mathrm{~cm}^{2}$.

\section{Discussion}

Primary fascial closure during HVR has been adopted by a number of centres. Several techniques have been used for closure of the hernial defect to restore abdominal wall anatomy, including intracorporeal closure with robotic arms or extracorporeal closure using either transfacial sutures or open closure. The main concerns regarding the preferable surgical technique are the recurrence rate and the associated complications rate. With the presented technique, we show that the recurrence rate was $3.6 \%$, which is comparable to published in literature. Postoperative seroma formation occurred in 16.1\%; however, all were managed conservatively. Chronic pain occurred in $3.6 \%$ of patients, those patients which required long-term input from pain clinic review.

Hernia recurrence is one of the main outcomes of interest in hernia surgery, due to its consequences for patient outcomes as well as the financial burden associated with it [11].

Hernia recurrence is multifactorial; however, hernia size was identified as a significant risk factor for 
predicting recurrence. In particular, recurrence was more likely with defects wider than $10 \mathrm{~cm}$ and the size of the defect is an independent predictor for recurrence $[7,12]$. In addition, high $\mathrm{BMI}\left(\mathrm{BMI}>25 \mathrm{~kg} / \mathrm{m}^{2}\right)$ was also associated with recurrence: the recurrence rate is $18 \%$ in patients with $\mathrm{BMI}>25$ in comparison to $5 \%$ in those with $\mathrm{BMI}<25$. In patients with BMI over $30 \mathrm{~kg} / \mathrm{m}^{2}$, the recurrence rate is particularly increased $[13,14]$. BMI $>30 \mathrm{~kg} / \mathrm{m}^{2}$ is a known risk factor for ventral hernias, which is majority of patients in this study. The majority of patients with ventral hernias have a BMI $>30 \mathrm{~kg} / \mathrm{m}^{2}$ in literature as in our study, the recurrences occurred in cases where the diameter was $>10 \mathrm{~cm}$ which is in agreement with published literature.

Studies have shown no significant difference between open and laparoscopic repair on recurrence rates [7-15]. The majority of hernia recurrences occurred in the first 2 years after both open and laparoscopic treatment. However, open repair appeared to be associated with recurrences after the 2 years [16].

The differences in facial closure technique used in different studies may have a role in variations in the reported recurrence rates. Intracorporeal suture closure of the defect reduced the recurrence rate and complications post repair; however, this did not reach statistical significance. Intracorporeal suturing is technically challenging and prolonged the operative time significantly [17]. This is further supported by Zeiken et al. [18], where no statistical significant difference in recurrence between transcutaneous and intracorporeal closures was observed; however, the recurrence cases appeared to occur in the transcutaneous closure group and not in intraperitoneal closure.

Transcutaneous extracorporeal closure of the defect can also be used; however, there are limits to the size of the defect that can be closed with this technique due to technical difficulties in closing defects wider than $10 \mathrm{~cm}$, as this places high tension on the abdominal wall. Shoe lacing is another type of transcutaneous closure, which acts by redistributing tension at the site of the figure-of-eight stitches over the large surface of the mesh. There were no recurrences detected with this technique at 16 months follow-up, with no seromas [19]. This is similar to Zeiken et al. [18], who did not find a statistically significant difference in recurrence rates between closure $(6.25 \%)$ and non-closure groups $(19.18 \%)$. This shows that the closure technique is crucial in affecting the outcomes of interest.

One of the concerns after laparoscopic repair is seroma formation, as the hernia sac is not routinely excised. However, if the fascia is closed and the sac is dissected and excised, we show that seroma formation and its related complaints were reduced.

The only randomised multicentre study of laparoscopic hernia versus a hybrid approach reported a seroma rate of $31 \%$ clinically and $45 \%$ based on ultrasound examination [20]. The rate of seroma formation was significantly higher in the laparoscopic approach in comparison to the hybrid approach [20]. The technique used in the randomised study was similar to that used in the present report. The rate of seroma formation was reported at $12.6 \%$, which could be due to lower patient numbers and potentially lower detection, as patients were not routinely reviewed [20].

Rates of seroma formation reported in the literature range from 0 to $11.4 \%$ among patients undergoing PFC during LVHR [19, 21-23]. On the other hand, few reports found no effect of defect closure in reducing postoperative wound morbidity and seroma formation, even when stratifying by hernia size, patient age, gender, and BMI [24, 25]. Zeichen et al. [18] found the opposite trend, with seroma forming in $11.4 \%$ of patients undergoing a hybrid technique but in only $4.3 \%$ of those undergoing laparoscopic repair.

Despite the initial thought that primary closure of the defect increases postoperative pain, chronic and postoperative pain were not shown to be different to standard laparoscopic repair. Not many studies have reported postoperative and chronic pain as an outcome. Chronic pain was comparable to that of laparoscopic repair [26, 27]. In addition, pain on the first postoperative day was found to be greater than with laparoscopy. However, no specific postoperative analgesic protocol was defined in this study. In addition, the overall cosmetic effect and patient satisfaction were greater with defect closure [21, 27].

Future randomised controlled trials are required with standardisation of both operative approach and postoperative management, to allow direct comparisons with careful assessment of patient-centred endpoints including quality of life and postoperative pain. There are huge variations in facial closure technique, which can explain differences in outcomes. Prospective randomized controlled trials assessing the closure techniques used in hybrid repair should address the following question: Is extracorporeal closure superior to intracorporeal closure of fascial defect? In addition to assessment of patient outcomes, cost effectiveness must be taken into consideration due to the financial implications of hernia repair and its complications for health services.

This study has a number of limitations. First, it is a retrospective study. This retrospective nature introduces bias. Secondly, this study was based at a single hospital site, and the patient cohort may not represent the general population. Third, data regarding postoperative and chronic pain relied on the information reported in clinical follow-up and re-attendances to hospital, and not on validated questionnaires. Finally, although all patients had postoperative clinical followup, improved objective follow-up would strengthen results in assessing the study outcomes.

In conclusion, this study demonstrates that hybrid ventral hernia repair with sac excision and defect clo- 
sure is a technique that is associated with low recurrence rates in long follow-up data. Despite excising the sac and closing the defect in an open technique, overall morbidity and postoperative pain were low. We believe that this approach is a safe and accepted technique with reproducibility amongst surgeons.

Funding Ms. Sara Jamel is funded by the Guts UK Charity. The views expressed are those of the authors and not necessarily those of the NHS, the Guts UK or the Department of Health.

Funding Open access funding provided by Imperial College London.

Conflict of interest S. Jamel, S.M. Hakky, K. Tukanova, S. Huf, S. Markar and S. Purkayastha declare that they have no competing interests.

Open Access This article is licensed under a Creative Commons Attribution 4.0 International License, which permits use, sharing, adaptation, distribution and reproduction in any medium or format, as long as you give appropriate credit to the original author(s) and the source, provide a link to the Creative Commons licence, and indicate if changes were made. The images or other third party material in this article are included in the article's Creative Commons licence, unless indicated otherwise in a credit line to the material. If material is not included in the article's Creative Commons licence and your intended use is not permitted by statutory regulation or exceeds the permitted use, you will need to obtain permission directly from the copyright holder. To view a copy of this licence, visit http://creativecommons.org/licenses/by/4.0/.

\section{References}

1. Halm JA, Lip H, Schmitz PI, et al. Incisional hernia after upper abdominal surgery: a randomised controlled trial of midline versus transverse incision. Hernia. 2009;13(3):275-80.

2. Kurzer M, Kark AE, Wantz GE. Surgical management of abdominal wall hernia. London: Martin Dunitz; 1999.

3. Kingsworth A, LeBlanc K. Hernias: inguinal and incisional. Lancet. 2003;362:1561-71.

4. Office for National Statistics Ageing. Fastest increase in the 'Oldest Old'. London: ONS. 2010. http://www.statistics.gov. uk/cci/nugget.asp?id=949. Accessed 18/06/2019

5. LeBlanc KA, Booth WV. Laparoscopic repair of incisional abdominal hernias using expanded polytetrafluoroethylene: preliminary findings. Surg Laparosc Endosc. 1993;3(1):39-41.

6. Rajkumar JS. Chopra P and chintamani. Basic physics revisted for a surgeon. Indian J Surg. 2015;77:169-75.

7. Eker H, Bibi H, Duunen M, et al. Laparoscopic vs open incisional hernia repair. JAMASurg. 2013;148:259-63.

8. Lian MK, Berger RL, Li LT, et al. Outcomes of laparoscopic vs open repair of primary ventral hernias. JAMA Surg. 2013;148:1043-8.

9. Kurmann A, Visth E, Candinas D, et al. Long-term follow-up of open and laparoscopic repair of large incisional hernias. World J Surg. 2011;35:297-301.
10. Tse GH, Stutchfield BM, Duckworth AD, et al. Pseudorecurrence following laparoscopic ventral and incisional hernia repair. Hernia. 2010;14:583-7.

11. Davilla DG, Parikh N, Frelich MJ, et al. The increased cost of veral hernia recurrence: a cost analysis. Hernia. 2016;20:811-7.

12. Hesselink VJ, Luijendijk RW, de Wilt JH, et al. An evaluation of risk factors in incisional hernia recurrence. Surg Gynecol Obstet. 1993;176:228-34.

13. SchumacherOP, Peiper C, Lörken M, etal. Long-term results afterSpitzy'sumbilicalherniarepair. Chirurg. 2003;74:50-4.

14. Franklin ME Jr, Gonzalez JJ Jr, Glass JL, et al. Laparoscopic ventral and incisional hernia repair: An 11-year experience. Hernia. 2004;8:23-7.

15. Sauerland S, Walgenbach M, Habermalz B, et al. Laparoscopic versus open surgical techniques for ventral or incisional hernia repair. Cochrane Database Syst Rev. 2011;3:CD007781.8.

16. Singhal V, Szeto P, VanderMeer T, et al. Ventral hernia repair: outcomes change with long-term follow-up. JSLS. 2012;16(3):373-9.

17. Gonzalez AM, Romero RJ, Seetharamaiah R, et al. Laparoscopic ventral hernia repair with primary closure versus no primary closure of the defect: potential benefits of the robotic technology. Int J Med Robot. 2015;11(2):120-5.

18. Zeichen MS, Lujan HJ, Mata WN, et al. Closure versus nonclosure of hernia defect during laparoscopic ventral hernia repair with mesh. Hernia. 2013;17:589-96.

19. Orenstein SB, Dumeer JL, Monteagudo J, et al. Outcomes of laparoscopic ventral hernia repair with routine defect closure using "shoelacing" technique. Surg Endosc. 2011;2011:1452-7.

20. Ahonen-Siirtola M, Nevala T, Vironen J, et al. Laparoscopic versus hybrid approach for treatment of incisional ventral hernia: a prospective randomized multicentre study of 1-month follow-up results. Hernia. 2018;22:1015-22.

21. Rea R, Falco P, Izzo D, et al. Laparoscopic ventral hernia repair with primary transparietal closure of the hernia defect. BMCSurg. 2012;12(Suppl 1):S33.

22. Nguyen DH, Nguyen MT, Askenasy EP, et al. Primary fascial closure with laparoscopic ventral hernia repair: systematic review. World JSurg. 2014;38:3097-104.

23. Chelala E, Barake H, Estievenart J, et al. Long-term outcomes of 1326 laparoscopic incisional and ventral hernia repair with the routine suturing concept: a single institution experience. Hernia. 2016;20:101-10.

24. Wennergren JE, Askenasy EP, Greenberg JA, et al. Laparoscopic ventral hernia repair with primary fascial closure versus bridged repair: a risk-adjusted comparative study. SurgEndosc. 2016;30:3231-8.

25. Papageorge CM, FunkLM, Poulose BK, et al. Primary fascial closure during laparoscopic ventral hernia repair does not reduce 30-day wound complications. Surg Endosc. 2017;31:4551-7.

26. Clapp ML, Hicks SC, Awad SS, Liang MK. Trans-cutaneous closure of central defects (TCCD) in laparoscopic ventral hernia repairs (LVHR). World JSurg. 2013;37(1):42-51.

27. Light D, Bawa S. Trans-fascial closure in laparoscopic ventral hernia repair. Surg Endosc. 2016;30:5228-31.

Publisher's Note Springer Nature remains neutral with regard to jurisdictional claims in published maps and institutional affiliations. 